\title{
Fine Needle Aspiration Cytology versus Histopathological Examination in Head and Neck Lesions
}

\author{
Anju Saraf, Sachin Gupta, Amit Manhas, Parmod Kalsotra, K C Goswami \\ Ex Senior Resident Department of ENT \& HNS, GMC Jammu \\ Assistant Professor, Department of ENT \& HNS, ASCOMS, Sidhra, Jammu \\ Lecturer, Department of Urology Anaesthesia, Superspeciality Hospital, GMC Jammu \\ Professor, Department of ENT \& HNS, GMC Jammu \\ Professor, Department of Pathology, ASCOMS, Sidhra, Jammu
}

\begin{abstract}
Aim: To study the cytomorphological features of head and neck lesion using fine needle aspiration cytology (FNAC) and compare its results with histopathology of the same lesion, thereby, to determine the diagnostic efficacy of FNAC.

Methods: FNAC results of 120 patients presenting with head and neck swellings to Dept. of ENT and Head and Neck Surgery, Govt. Medical College, Jammu were analysed and categorized into benign and malignant conditions. The cytological findings of these lesions were compared to histopathology findings of the same lesion in 96 patients and the efficacy of FNAC was determined in terms of sensitivity, specificity and accuracy. Results: The overall sensitivity, specificity and accuracy of FNAC in cases of head and neck swellings in the present study is $86.7 \%, 92.2 \%$ and $95.5 \%$ respectively. It is $100 \%$ sensitive, specific and accurate in case of lymph node swellings while it is $72.3 \%$ \& $75 \%$ sensitive, $86.6 \%$ \& $94.4 \%$ specific and $89.5 \%$ \& $92.5 \%$ accurate in cases of thyroid swellings and salivary gland swellings respectively.

Conclusion: Simple technique, high compliance, cost effectiveness and high specificity make FNAC as the first diagnostic invasive procedure in the management of head and neck swellings, despite some limitations.
\end{abstract}

Keywords: FNAC, Histopathology, Salivary gland, Thyroid, Lymph node.

\section{Introduction}

The tissue diagnosis of head and neck swelling/tumor is possible only by means of cytology either FNAC, trucut or by open biopsy, sometimes supplemented by immunohistochemistry. In cytology the role of trucut biopsy and open biopsy have been superseded by FNAC with the advent of more skilled cytopathologist. FNAC is of particular relevance in Head and Neck region because of the easy accessibility of target sites, excellent patient compliance due to minimally invasive nature of technique and the important aspect of avoidance of surgery. FNAC also affords a practical means of rationally planning surgery.$^{[1]}$ In the hands of skilled and committed cytologist accuracy exceeds $92 \%$ with a few false negatives and very occasionally a false positive report. ${ }^{[2]}$

FNAC is also valuable in the diagnosis of inflammatory, infectious and degenerative conditions in which samples can be used for microbiological and biochemical analysis in addition to cytological preparations. ${ }^{[3]}$ It is highly cost-effective and accurate as a first line investigative technique with differential diagnosis including reactive hyperplasia/inflammatory conditions, granulomatous disorders and malignancy, confirmation requiring further investigations, surgical intervention or clinical follow up. ${ }^{[4]}$

Although FNAC is a very useful technique still there are some diagnostic pitfalls and limitations. Some benign conditions may display highly deceptive cytological features e.g., nodular fasciitis or granulomatous lymphadenopathy and some benign tumors such as adenoma of thyroid or parathyroid may contain highly pleomorphic cells leading to a false impression of malignancy. By contrast some malignant tumors such as well differentiated follicular carcinoma of the thyroid appears deceptively bland. Quite occasionally, large quantities of necrotic fluid debris may be aspirated from malignant lesions and cytologists may regard it as branchial cyst. ${ }^{[5]}$ Also FNAC does not reliably distinguish benign from malignant primary salivary gland neoplasms. ${ }^{[6]}$

The ability of FNAC to diagnose all kinds of lesions in head and neck region has been confirmed by numerous case reports and case series. More studies are, however, required to determine the efficacy of FNAC in head and neck region by cytohistopathological correlation and this being the reason for undertaking the present study.

\section{Materials and Methods}

The study was conducted on 120 patients presenting with head and neck swellings in the ENT OPD and indoor of S.M.G.S Hospital, Government Medical College, Jammu for a period of two and a half years. All 
the patients included in the study were subjected to detailed history and complete ENT examination (including indirect laryngoscopy and posterior rhinoscopy), general physical examination, haematological examination and radiological examination particularly X-ray chest and soft tissue neck (lateral view). Special investigations like CT scan, MRI, USG, thyroid profile and thyroid scans were done in relevant cases. All the cases were subjected to FNAC but surgical biopsy was done only in 96 cases as 24 patients did not give consent for surgical procedure. FNACs were performed under the supervision of cytopathologist in the Department of Pathology, Government Medical College, Jammu.

Procedure was explained to the patient and attendants and written informed consent was taken. Aspiration was carried out using $20 \mathrm{ml}$ disposable syringe attached to 20 gauge needle and with a special handle. The needle was detached after aspiration by allowing the pressure to equalize before withdrawl and air was sucked into the syringe. The needle was reattached and material ejected forcefully onto 4-6 clear glass slides and smears were prepared. One or two wet smears were immediately fixed in 95\% ethyl alcohol and others were air dried and routinely stained by Papani Colau (PAP) and May-Grunwald Giemsa (MGG) stains respectively. Special staining like Ziehl- Neelsen stain for acid fast bacilli (AFB), alcain blue - PAS for mucus was done wherever required. The stained smears were examined by cytopathologist and the reporting of FNAC was done and recorded.

As per the FNAC report, relevant investigations were done to establish the diagnosis and surgical intervention was planned which was discussed with patients and their attendants. All the patients were selected for surgery but 24 patients refused surgical intervention. The surgical procedure was done under general and local anaesthesia, as was suitable for the particular case. The surgical specimen obtained was fixed in $10 \%$ neutral buffered formalin and subjected to gross examination, processing, paraffin embedding, section cutting, staining by haematoxylin and eosin and mounting by DPX. The stained sections were examined by the cytopathologist. Cytomorphological features of different diseases were studied. The FNAC and the histopathological examinations of the same lesion were compared by the cytopathologist. The efficiency of FNAC in diagnosing different diseases was calculated in terms of sensitivity, specificity and accuracy.

\section{Observations}

120 cases with head and neck swellings were included in the present study and FNAC was done in all the patients but excision biopsy could be done in 96 patients as rest of them did not give consent for surgery. The observations are given as follows:

The various head and neck masses submitted to FNAC and excision biopsy included those arising from cervical lymph nodes, thyroid gland, salivary gland, blood vessels and miscellaneous tissue. The miscellaneous group included various cervical cysts and mandibular swellings. These are shown in table 1.

Table 1: Distribution of swellings according to the site involved.

\begin{tabular}{|l|l|l|}
\hline Site & Number of cases & Percentage $(\%)$ \\
\hline Cervical lymph nodes & 20 & 20.83 \\
\hline Thyroid & 32 & 33.33 \\
\hline Salivary glands & 36 & 37.5 \\
\hline Miscellaneous & 8 & 8.33 \\
\hline Total & 96 & 100 \\
\hline
\end{tabular}

The swelling arising from the salivary glands formed the largest group (37.5\%). Next in frequency were the masses from the thyroid glands (33.33\%) and then the cervical lymph nodes (20.83\%). The miscellaneous group included $8(8.33 \%)$ cases which included 4 cysts and 2 swellings each arising from mandible and from the blood vessels (cavernous haemangioma). The swelling from mandible was finally diagnosed as non-Hodgkin's lymphoma.

58 cases $(60 \%)$ were females while 38 cases $(40 \%)$ were males. The youngest patient in the study was a male aged 3 years while the elder most patient was a 65 year old female, who had come with a thyroid swelling. Predominantly, maximum number of cases were in the age group of 21-30 and 41-50 years with the distribution of cases in various age groups being shown in table 2 .

Table 2: Age distribution.

\begin{tabular}{|l|l|l|}
\hline Age in years & Number of cases & Percentage (\%) \\
\hline$<10$ & 10 & 10.41 \\
\hline $11-20$ & 18 & 18.75 \\
\hline $21-30$ & 24 & 25 \\
\hline $31-40$ & 14 & 14.58 \\
\hline $41-50$ & 20 & 20.83 \\
\hline $51-60$ & 8 & 8.33 \\
\hline $61-70$ & 2 & 2.08 \\
\hline
\end{tabular}


The patients presented with masses of various duration ranging from 10 days to 20 years, with details shown in Graph 1.

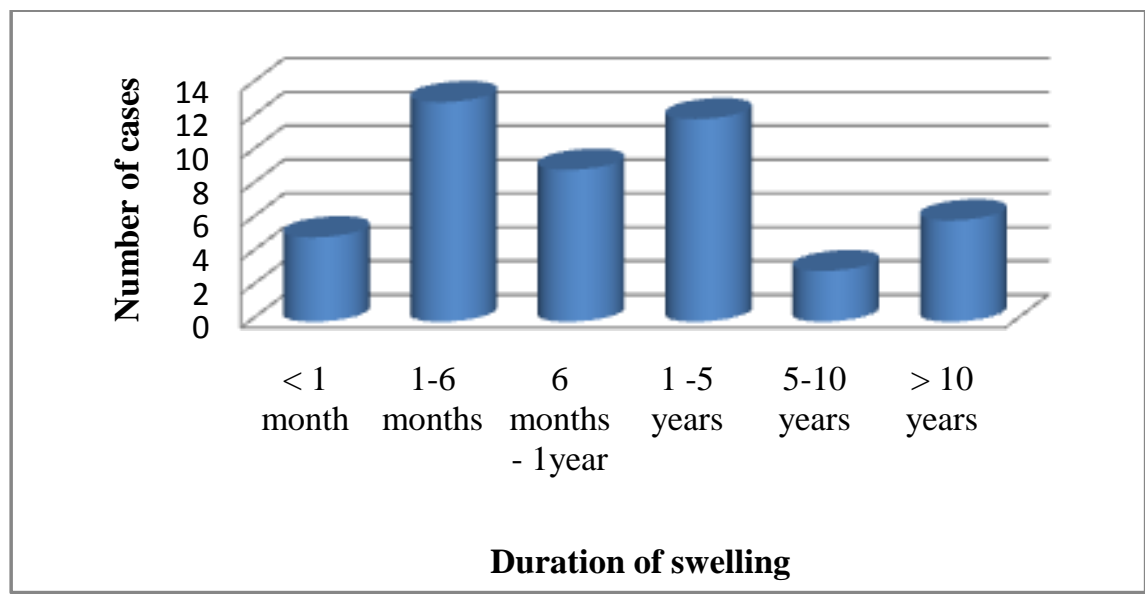

The presenting complaint in all of the cases studied was swelling in the head and neck region. Many of the patients presented with other symptoms in association with the swelling. These are shown in table 3. Among the cases studied, $10.41 \%$ had associated pain, $4.06 \%$ gave history of discharge from the swelling, $6.25 \%$ cases of thyroid swelling which constituted $2.08 \%$ of the total cases complained of difficulty swallowing and the same proportion of the thyroid swelling complained of difficulty breathing.

Table 3: Presentation of various symptoms.

\begin{tabular}{|l|l|l|}
\hline Symptoms & Number of cases & Percentage (\%) \\
\hline Swelling & 96 & 100 \\
\hline Swelling + Pain & 10 & 10.41 \\
\hline Swelling + Discharge & 4 & 4.16 \\
\hline Swelling + Dysphagia & 2 & 2.08 \\
\hline Swelling + Breathing problem & 2 & 2.08 \\
\hline
\end{tabular}

There were 20 cases of cervical lymphadenopathy. The various groups involved are shown in table 4 .

Table 4: Various levels of lymph nodes involved $(n=20)$.

\begin{tabular}{|l|l|l|}
\hline Nodes (level) & Number of cases & Percentage (\%) \\
\hline $\begin{array}{l}\text { Jugular } \\
\text { chain - II, III, IV) }\end{array}$ & 8 & 40 \\
\hline Posterior triangle (V) & 4 & 20 \\
\hline Multiple sites & 8 & 40 \\
\hline Total & 20 & 100 \\
\hline
\end{tabular}

Thyroid swelling comprised of 32 patients $(33.33 \%)$ of all the cases, with patients presenting either with diffuse enlargement of thyroid (4/32 cases, $12.5 \%)$ or with a nodular swelling, either a solitary nodule $(10 / 32$ cases, $31.25 \%)$ or a multinodular swelling (18/32 cases, $56.25 \%)$.

There were a total of 36 cases of salivary gland swelling with maximum number being that of parotid swellings (22 cases, $61.11 \%$ ) followed by submandibular (12 cases, 33.33\%) with two cases involving a small salivary gland (buccal mucosa).

\section{Results}

Among the 32 cases of thyroid swelling, 22 patients $(68.75 \%)$ were finally diagnosed as colloid goiter, 4 patients $(12.5 \%)$ each, had malignancy and thyroid adenoma, respectively with two patients being reported as normal on HPE. Two cases of thyroid swellings were reported as colloid goitre on FNAC but HPE reported it to be follicular adenoma. Two patients with FNAC report as colloid goitre were finally reported as papillary carcinoma on HPE, after surgery while 2 cases reported earlier as papillary carcinoma on FNAC were reported to be normal tissue on HPE. Thus there were 2 false negative and 2 false positive cases for thyroid malignancy. Table $5 \& 6$ shows the final diagnosis on HPE and comparative results of FNAC and HPE respectively. 
Fine Needle Aspiration Cytology Versus Histopathological Examination In Head...

Table 5: Final diagnosis (HPE) of swellings at various sites in head and neck ( $\mathrm{n}=96)$.

\begin{tabular}{|c|c|c|c|c|c|}
\hline \multicolumn{2}{|l|}{ Site } & Type & Diagnosis & Number of cases & Percentage (\%) \\
\hline \multirow{4}{*}{\multicolumn{2}{|c|}{$\begin{array}{l}\text { Thyroid } \\
(\mathrm{n}=32) \\
(33.33 \%)\end{array}$}} & \multirow[t]{3}{*}{ Beingn } & Colloid & 22 & 22.91 \\
\hline & & & Adenoma & 4 & 4.16 \\
\hline & & & Normal & 2 & 2.08 \\
\hline & & Malignant & Papillary carcinoma & 4 & 4.16 \\
\hline \multirow{8}{*}{$\begin{array}{l}\text { Salivary } \\
\text { Gland } \\
(\mathrm{n}=36) \\
(37.5 \%)\end{array}$} & \multirow[t]{3}{*}{$\begin{array}{l}\text { Parotid } \\
(\mathrm{n}=22)\end{array}$} & Benign & $\begin{array}{l}\text { Pleomorphic } \\
\text { oma }\end{array}$ & 14 & 14.58 \\
\hline & & Malignant & $\begin{array}{l}\text { Mucoepidermoid } \\
\text { noma }\end{array}$ & 6 & 6.25 \\
\hline & & & Fibrosarcoma & 2 & 2.08 \\
\hline & \multirow[t]{3}{*}{$\begin{array}{l}\text { Submandibular } \\
(\mathrm{n}=12)\end{array}$} & Benign & $\begin{array}{l}\text { Pleomorphic } \\
\text { oma }\end{array}$ & 8 & 8.33 \\
\hline & & & \begin{tabular}{|l|} 
Inflammatory \\
\end{tabular} & 4 & 4.16 \\
\hline & & & Malignant & Nil & Nil \\
\hline & \multirow{2}{*}{$\begin{array}{l}\text { Small salivary } \\
(\mathrm{n}=2)\end{array}$} & Benign & \begin{tabular}{|l} 
Pleomorphic \\
oma
\end{tabular} & 2 & 2.08 \\
\hline & & & Malignant & Nil & Nil \\
\hline \multirow{3}{*}{$\begin{array}{l}\text { Lymphad- } \\
\text { athy } \\
(\mathrm{n}=20) \\
(20.83 \%)\end{array}$} & \multicolumn{3}{|c|}{ Non- specific } & 12 & 12.5 \\
\hline & \multicolumn{3}{|c|}{ Tubercular } & 6 & 6.25 \\
\hline & \multicolumn{3}{|c|}{ Lymphoma } & 2 & 2.08 \\
\hline \multirow{3}{*}{$\begin{array}{l}\text { Miscellaneous } \\
(\mathrm{n}=8) \\
(8.33 \%)\end{array}$} & \multicolumn{3}{|c|}{ Cavernous haemengioma } & 2 & 2.08 \\
\hline & \multicolumn{3}{|c|}{$\begin{array}{c}\text { Cervical cysts } \\
\text { Swelling of mandible (lymphoma) }\end{array}$} & 4 & 4.16 \\
\hline & \multicolumn{3}{|c|}{ Swelling of mandible (lymphoma) } & 2 & 2.08 \\
\hline \multicolumn{4}{|c|}{ Total } & 96 & 100 \\
\hline
\end{tabular}

Table 6: Comparative results of FNAC and HPE in Head and Neck swellings regarding malignancy

\begin{tabular}{|c|c|c|c|c|c|}
\hline \multirow{2}{*}{ Tissue } & \multirow{2}{*}{ Total } & \multicolumn{2}{|c|}{ FNAC } & \multicolumn{2}{c|}{ HPE } \\
\cline { 3 - 6 } & & Malignant & Benign & Malignant & Benign \\
\hline Lymph node & 20 & 2 & 18 & 2 & 18 \\
\hline Thyroid & 32 & 4 & 28 & 4 & 28 \\
\hline Salivary glands & 36 & 2 & 34 & 8 & 28 \\
\hline Miscellaneous & 8 & 2 & 6 & 2 & 6 \\
\hline Total & 96 & 10 & 86 & 16 & 80 \\
\hline
\end{tabular}

Fig 1A and 1B show the features of papillary carcinoma of thyroid on FNAC and histopathology respectively in the same patient. Fig 2 shows the features of nodular goitre on FNAC and HPE in the same case.

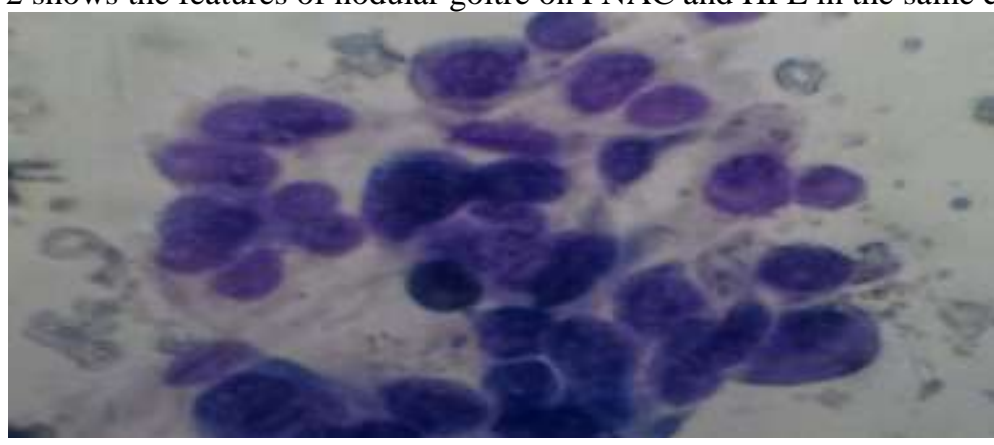

Fig 1A: FNAC of thyroid showing cytological features of papillary carcinoma (MGG X 400)

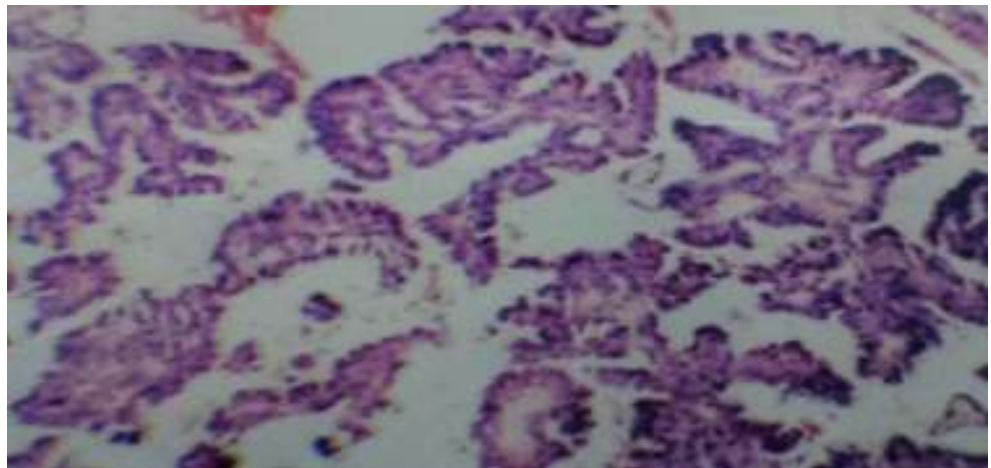

Fig 1B: Sections of the thyroid tissue of the same patient showing papillary carcinoma of thyroid (H\&E X 100 

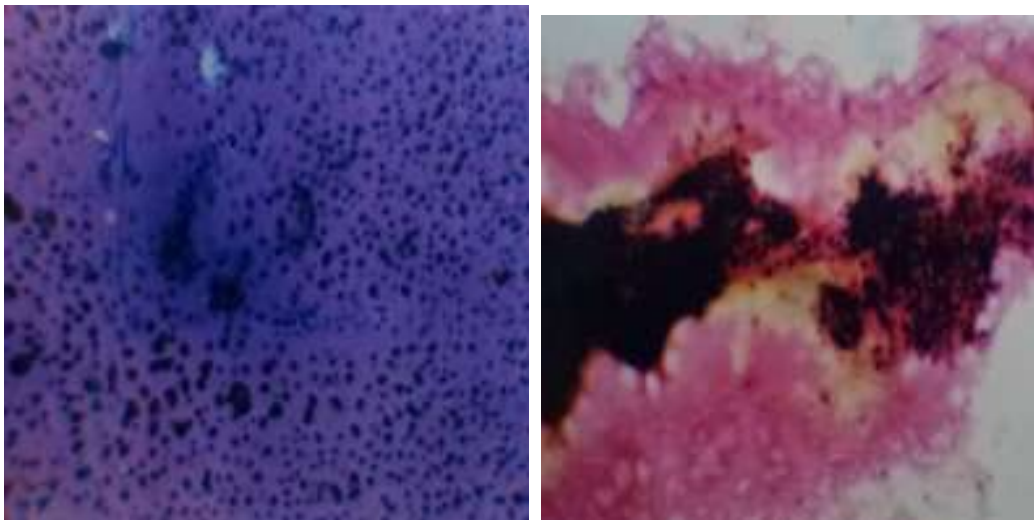

Fig 2A: FNAC of thyroid tissue showing cytological features of nodular goiter with abundant colloid

Fig 2 B: FNAC of thyroid of same case showing and scattered follicular cells . sheets of follicular cells with abundant pink colloid

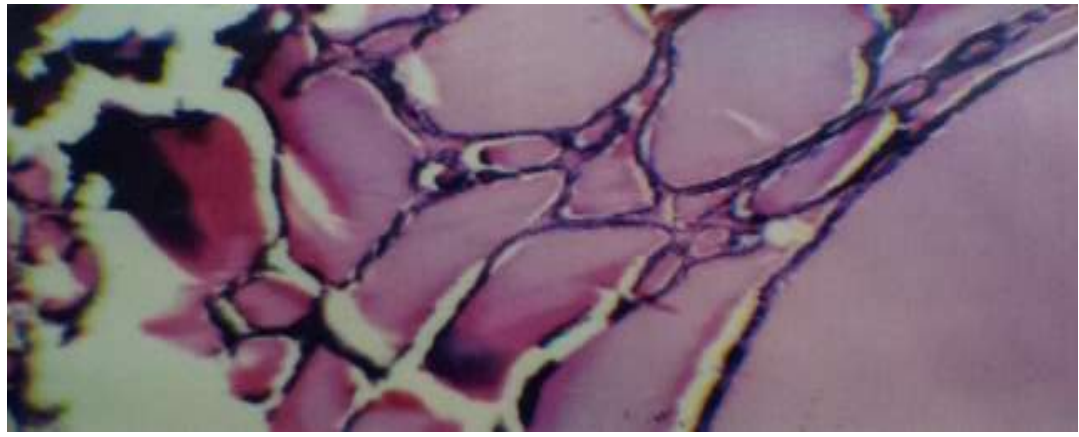

Fig 2C: Histology of the above case confirms nodular goiter.

On HPE of parotid gland $(n=22), 14$ cases $(63.64 \%)$ were found benign while 8 cases $(36.36 \%)$ were found malignant. Among the benign, all were pleomorphic adenoma while among the 8 malignant cases, 6 $(75 \%)$ were muco-epidermoid carcinomas while $2(25 \%)$ were fibrosarcoma. In submandibular swellings $(n=12)$ all cases were benign on HPE, with 8 cases being that of pleomorphic adenoma and 4 being of inflammatory origin. FNAC missed 6 malignant cases in the salivary gland group. Fig 3A and 3B show features of pleomorphic adenoma of parotid on FNAC and HPE respectively.

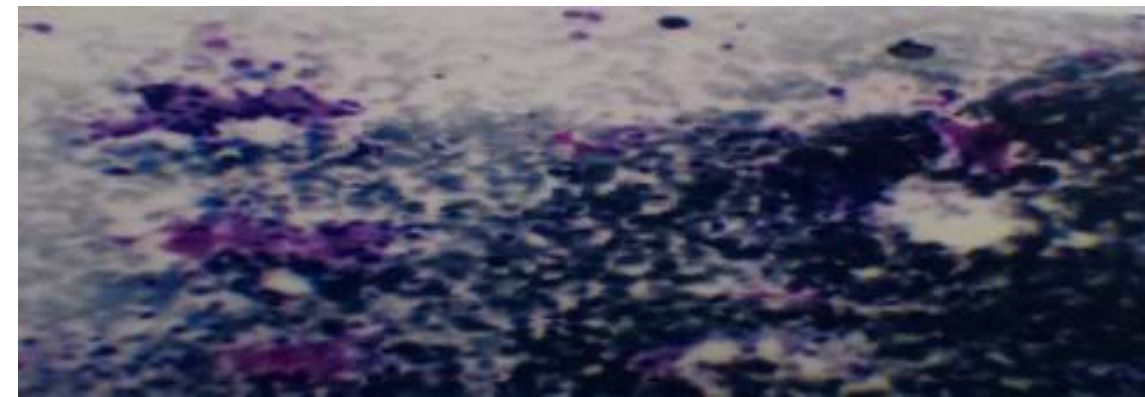

Fig 3A: FNAC of parotid gland showing clusters of epithelial cells with pink fibrillary stroma leomorphic adenoma.

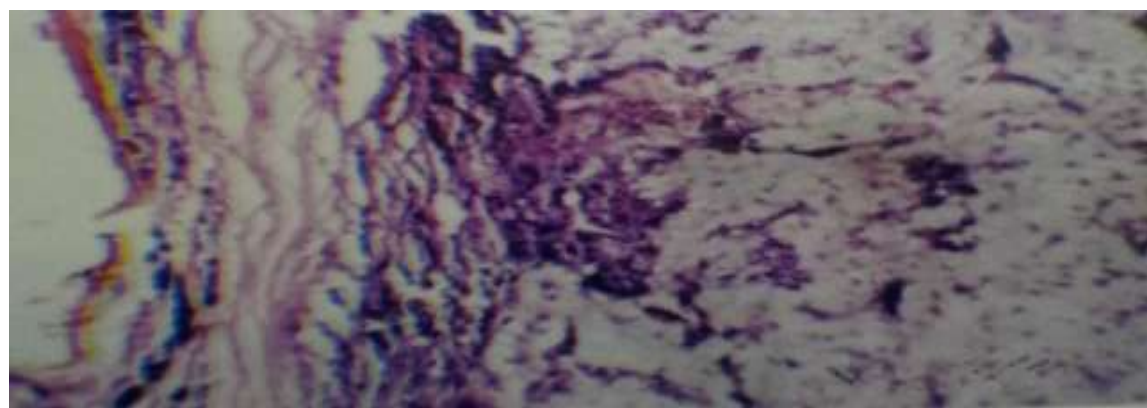

Fig 3B: Histology confirms Pleomorphic adenoma in the above case. 
Cervical lymphadenopathy comprised 20 cases (21\%), among these, 18 (90\%) were diagnosed as benign and 2 cases (10\%) as malignant on HPE. Among the benign group, 6 cases $(33.33 \%)$ were diagnosed as tubercular and $12(66.66 \%)$ as non-specific lymphadenopathy. The miscellaneous group had $8(8.33 \%)$ cases, four out of these were cervical cysts and two cases each of cavernous haemangioma and swelling from mandible diagnosed as non-Hodgkin's lymphoma on HPE. The efficacy of FNAC to diagnose head and neck swellings in terms of sensitivity, specificity and accuracy is shown in table 7

Table 7: Efficacy of FNAC to diagnose head and neck swelling.

\begin{tabular}{|l|l|l|l|l|}
\hline \multicolumn{2}{|l|}{ Site } & Sensitivity $(\%)$ & Specificity $(\%)$ & Accuracy $(\%)$ \\
\hline $\begin{array}{l}\text { Lymph node (benign and } \\
\text { nant) }\end{array}$ & 100 & 100 & 100 \\
\hline \multirow{2}{*}{$\begin{array}{l}\text { Thyroid } \\
\text { Swelling }\end{array}$} & Benign & 93.3 & 50 & 87.5 \\
\cline { 2 - 5 } & Malignant & 50 & 92.8 & 87.5 \\
\cline { 2 - 5 } & Overall & 72.3 & 86.6 & 89.5 \\
\hline \multirow{3}{*}{$\begin{array}{l}\text { Salivary } \\
\text { Gland }\end{array}$} & Benign & 100 & 25 & 83.3 \\
\cline { 2 - 5 } & Malignant & 25 & 100 & 83.3 \\
\cline { 2 - 5 } & Overall & 75 & 94.4 & 92.5 \\
\hline Miscellaneous & & 100 & 100 & 100 \\
\hline \multirow{3}{*}{ Total } & Benign & 97.5 & 50 & 89.5 \\
\cline { 2 - 5 } & Malignant & 50 & 97.5 & 89.5 \\
\cline { 2 - 5 } & Overall & 86.7 & 92.2 & 95.5 \\
\hline
\end{tabular}

\section{Discussion}

The differential diagnosis of a head and neck swelling covers a broad spectrum of diseases with differing implications for management. Common causes of head and neck swellings include diseases of thyroid, salivary gland, lymph nodes, cysts etc. However, one half of asymmetrical head and neck masses in adults are reported to be malignant, either primary (usually lymphoma) or secondary (usually carcinoma). ${ }^{[7]}$

Earlier, incisional or excisional biopsy used to be the only way of diagnosis which was associated with its inherited surgical and anaesthetic complications. To avoid these complications, FNAC was introduced in the early $20^{\text {th }}$ century. Aspiration cytology has the advantage of relatively less morbidity, quick procedure without need for any anaesthesia, less cost and almost without any contraindication. ${ }^{[8]}$

In this study, the male:female ratio was 40:60 which was in accordance with the studies in the past with Aslam et al. ${ }^{[9]}$, in a study of 104 cases of cervical lymphadenopathy, reporting a male:female ratio of 35:65 and Samiullah et al. ${ }^{[8]}$ in a study of 198 cases of head and neck masses, reporting it to be 36.6:73.4.

In the present study of 96 cases head and neck swellings, salivary gland swellings formed the largest group accounting for $36(37.5 \%)$ cases followed by the thyroid swelling forming $32(33.33 \%)$ cases of total study group. The lymph node enlargement formed $20(20.83 \%)$ cases while the miscellaneous group including 4 cysts, 2 mandibular swellings and 2 cavernous haemangiomas, accounted for $8.33 \%$ of the total cases. The distribution of the site was not in accordance with the literature. Samiullah et al. ${ }^{[8]}$ reported lymph node swelling as the largest group $(62.8 \%)$, followed by thyroid $(14.18 \%)$, salivary glands $(11.95 \%)$ and then the miscellaneous group (11.19\%). The variations could be because of referral system of the institute where the present study was conducted. Also, it could be attributed to more cases of salivary gland and thyroid swellings presenting to ENT OPD instead of surgical OPD.

In the present study, thyroid swellings formed $32(33.33 \%)$ cases of the total study. The various diagnosis confirmed by histopathology were colloid goiter in $22(68.75 \%)$ cases, thyroid adenoma in $4(12.5 \%)$ cases, malignancy (papillary carcinoma) in $4(12.5 \%)$ cases with $2(6.25 \%)$ cases being reported as normal tissue. Among 4 cases of malignancy, FNAC could identify only 2 cases while the other 2 were false negative. 2 other cases were falsely reported as malignancy on FNAC which actually came out to be colloid on HPE. Therefore a sensitivity of $50 \%$, specificity of $92.8 \%$ and accuracy of $87.5 \%$ was calculated in the present study while diagnosing 'malignancy' of thyroid by FNAC. Raimond et al. ${ }^{[10]}$ reported a sensitivity of $57-70 \%$ in a retrospective analysis of 890 patients with thyroid carcinomas, sensitivity was lowest for follicular carcinoma $(67 \%)$. Same was reported by Michael et al. ${ }^{[1]}$ who reported a sensitivity of $78.8 \%$ with FNAC and a false negative rate of $21 \%$. The inability to diagnose a malignancy in patients could sometimes be attributed to big size of swelling, as in the present study. The overall efficiency of FNAC in diagnosing thyroid swelling in the present study was found as -sensitivity $72.3 \%$, specificity $86.6 \%$ and accuracy $89.5 \%$ while Arda et al. ${ }^{[12]}$ reported an overall sensitivity, specificity and accuracy of $100 \%, 95 \%$ and $95 \%$ respectively.

In the present study, there were $22(61.11 \%)$ cases of parotid gland, 12 cases of submandibular gland $(33.33 \%)$ and $2(5.56 \%)$ cases of salivary gland swellings. In literature, Cajulis et al. ${ }^{[13]}$, Sousa et al. ${ }^{[14]}$, and Khandelkar et al. ${ }^{[15]}$, in a study of FNAC of salivary gland lesions with histopathological correlation, also reported parotid as the most commonly affected salivary gland. 
Pleomorphic adenoma was the only benign neoplastic lesion in the present study. The sensitivity of FNAC to detect pleomorphic adenoma was calculated to be $100 \%$ while specificity was $83.3 \%$. Khandelkar et al. ${ }^{[15]}$ also reported a $100 \%$ correlation of FNAC and HPE in cases of pleomorphic adenoma while Balakrishnan et al. ${ }^{[16]}$ reported a sensitivity of $92 \%$ for diagnosis of pleomorphic adenoma by FNAC.

The present study has proved very less efficient in diagnosing the malignant tumors of salivary glands. Out of 36 cases of salivary gland swelling, FNAC showed two cases of malignancy but on HPE, 8 cases of malignancy were diagnosed. Thus there was a high false negative rate resulting in a low sensitivity of FNAC for malignancy $(25 \%)$. No false positive case was found resulting in a $100 \%$ specificity rate for malignancy. Low sensitivity rate of FNAC for salivary gland has been documented in the literature. Balkrishnan et al. ${ }^{[6]}$, who reported a sensitivity rate of 58 to $96 \%$ with a specificity of 71 to $88 \%$, concluded that FNAC did not reliably distinguish a benign from malignant salivary gland tumor. Jayaram et al. ${ }^{[16]}$ studied, retrospectively, FNAC findings of 247 salivary gland lesions, reported a sensitivity of $87.7 \%$ and a specificity of $98 \%$ in diagnosing malignancy of parotid by FNAC. There was a 100\% correlation in cases of inflammatory diseases of salivary glands in the present study and Khandelkar et al. ${ }^{[15]}$ also reported a correlation of $100 \%$ while Klijanuko et al. ${ }^{17}$ reported a cytohistological correlation of $81.8 \%$ for chronic sialadenitis. In the present study, 20 cases of cervical lymphadenopathy were included with the sensitivity, specificity and accuracy of FNAC reported as $100 \%$ which is in accordance with literature. Chamyal et al ${ }^{[18]}$ reported a sensitivity, specificity and accuracy of 93.6, 97.6 and $88.3 \%$ respectively in a study of 110 of cervical lymph node masses while Aslam et al. ${ }^{9}$ reported an overall diagnostic accuracy of $92.3 \%$ in a study on 104 cases of head and neck lymphadenopathy.

The present study was efficient in diagnosing lymphomas, with four cases being diagnosed as lymphoma on FNAC and confirmed by HPE, with two of them presenting as mandibular swellings and two as cervical lymphadenopathy. These results were in accordance with the past results as reported by Bandyopadyay et al. ${ }^{[19]}$ and Chaturvedi et al. ${ }^{[5]}$

\section{Conclusion}

FNAC combined with clinical correlation is useful as a first line investigation in case of head and neck swellings. The limitations are in the large cysts or solid tumors, thyroid and salivary gland malignancies, thereby, a negative report in case of thyroid or salivary gland swelling should be accepted with caution. FNAC has a very high efficacy to diagnose cervical lymphadenopathy but in case of lymphomas, immunophenotyping should also be done. Despite its limitations, high specificity of FNAC makes it an important investigative tool to select those patients who need further investigation or biopsy. Also its cost-effectiveness, simple technique and high compliance rates makes FNAC as first diagnostic invasive procedure in the management of head and neck masses.

\section{References}

[1]. A Abrari , S. S. Ahmad, V Bakshi, Cytology in the otorhinolaryngologist's domain - a study of 150 cases, emphasizing diagnostic utility and pitfalls,Ind J Otolaryngol Head Neck Surg,54, 2002,107-10.

[2]. Stell and Maran, Assessment in head and neck surgery. Watkinsen JC, Gaze MN, Wilson JA, Butterworth Heinemanm 2000 ; 4 : 21.

[3]. S. R. Orell, G. F. Sterrett, S. N. Whalter, et al, Head and neck : Salivary gland. Manual and Atlas of Fine Needle Aspiration Cytology. Edinberg Churchill Livingstone $1999 ; 3: 38-72$.

[4]. V Koo, T. F. Lioe, R Spence, FNAC in the diagnosis of granulomatous lymphadenitis Ulster Med J, 75, $2006,59-64$.

[5]. S Chaturvedi, J.K.Mishra, N.C.Arya, et al, Cervical lymphadenopathy : Diagnostic role of district level hospitals. Ind J Preven Social Med,27, 1996,117-20.

[6]. K.B. Balkrishan, C.J. McMohan, Imrie J, et al, FNAC in the management of parotid mass, Surg J Coll Surg Edinb Irel,3, 2005

[7]. D.P. Slaughter, J. D. Marajakis, H. N. Southwick, Clinical evaluation of swellings in the neck Surg Clin N Amer, 36, $1956,3-9$.

[8]. Samiullah, M Aslam, A Hassan, et al, Fine needle aspiration cytology versus biopsy in head and neck swellings, Ind J Otolaryngol Head Neck Surg, 2005, 24-25.

[9]. M Aslam, S. M. Hassan, S. A. Hassan, Fine needle aspiration cytology versus histopathology in cervical lymphadenopathy, Ind J Otolaryngol Head Neck Surg, 52, 2000, 137-40.

[10]. W. H. G. Raimond, J Herman, Use and accuracy of FNAC in histologically proven thyroid carcinoma., Cancer, 90, 2000, 33034.

[11]. W. Y. Michael, O Demircan, PItuarti, et al, False negative fine needle aspiration cytology results delay treatment and adversely affect outcome in patients with thyroid carcinom, Thyroid, 14(3), 2004, 207-15.

[12]. I. S. Arda , S Wildirimn, B Demirhan, S Firat, Fine needle aspiration biopsy of thyroid nodules, Arch Dis Child, 85, $2001,313$.

[13]. R. S. Cajulis, Gokaslan, Fine needle aspiration biopsy of the salivary glands, Acta Cytologica 1997, 1412-19.

[14]. J Sousa, De Sa Oswald, Salivary gland tumours : an analysis of 62 cases, Ind J Cancer, 38, 2001, 38-45.

[15]. M. M. Khandelkar, A. N. Kavatkar, S. A. Prtankar, et al, FNAC of salivary gland lesions with histopathological correlation, Ind J Otolaryngol Head Neck Surg, 58, 2006, 246-48.

[16]. G Jayaram, A Verma , N Sood, et al, Fine needle aspiration cytology of salivary glands, J Pathol Med, 23, $1994,256-61$.

[17]. J Klijanuko, P Vielh, Salivary gland tumours. In : Orell SR, Monographs in Clinical Cytology, 15, 2000 .

[18]. P. C. Chamyal , K Sabarigirish , Clinico- Pathological Correlation study of cervical lymph node masses., Ind J Otolaryngol Head Neck Surg , 49, 1997, 402-5.

[19]. S. N. Bandyopadhyay , K. K. Roy , A Dasgupta, et al, Role of fine needle aspiration cytology in the diagnosis of cervical lymphadenopathy. Indian J Otolaryngol Head Neck Surg , 48, 1996, $289-93$. 